\title{
The adequate use of opioids and the position of the Latin American Federation of Associations for the Study of Pain
}

\author{
Uso adequado de opioide e a posição da Federação Latino Americana de Associações para o \\ Estudo da Dor
}

DOI 10.5935/2595-0118.20190018

The adequate consumption of opioids in developing countries is still a significant challenge as it can bring about the reflection on the issues involving the correct treatment of acute and chronic pain. The literature is classic in reporting that physicians find it difficult to prescribe opioids, and the patient to accept therapy, for fear of adverse effects or addiction. On the other hand, opioids, a gold standard in the treatment of cancer pain and other types of moderate or severe pain, have insufficient availability and access to the patient, either because of the cost or the health surveillance public policy. The poor education on the subject of pain in undergraduate and postgraduate courses in medical schools, the restrictive government policies for the purchase and distribution of opioids, the need for registration to acquire specific prescriptions, fear of addiction, and the use of opioids for illicit purposes, as well as cultural attitudes towards pain contribute to what the scientific community calls opiophobia ${ }^{1-5}$. This refers to the opioid crisis that developed countries face ${ }^{6}$. Paradoxically, this crisis deals precisely with the consequences of prolonged and indiscriminate use of opioids in developed countries, since there has been an increase in the number of reports of death and addiction related to these drugs. In Latin America, however, the incidence of abuse is around $1 \%{ }^{7}$. In fact, in our region, cocaine and marijuana are the substances that lead to problems of abuse. In this way, we are facing a new paradigm, where the look and the critical reading of the opiophobia must be differentiated and related to the global geographic and economic context. It suffices to say that the daily average dose of opioids consumption for statistical purposes is 150 (S-DDD). This dose is below the recommended by the literature, reflecting how much we have to improve to achieve optimal pain treatment ${ }^{8}$. Also, the global consumption of opioids is higher in developed countries, and $75 \%$ of the world population in underdeveloped or developing countries do not receive any painkillers proportionally to the intensity of pain?. Therefore, the Latin American Federation of Associations for the Study of Pain (FEDELAT), in its current management, gathered in São Paulo opinion leaders and representatives from several Latin American countries to publish a position on the measures necessary to reverse this situation and the impact of opiophobia in developing countries. This paper $^{10}$ to be published in the Pain Reports (already accepted for publication and in press) addresses the necessary measures to correct this problem, which include: 1) continuous education - promoting the training of professionals on the safe use of opioids, based on protocols and scientific evidence. The training can be with meetings with experts and educational materials on the institutional web platforms; 2) public policies -creating awareness among the leaders about the need to develop specific programs for the treatment of pain and national scientific recommendations for the use of opioids, facilitating the access and the prescription of these drugs correctly; 3) creation of an electronic prescription - allowing the registration of the opioid prescription, the patient's disease, the dose, the duration of the prescription, the pharmacy that provided the medicine and the monitoring of risks; 4) statistics -promoting the registration of hospital and outpatient use and distribution of opioids; 5) multidisciplinary care - encouraging the creation of clinics involving other health professionals who ensure the assessment, diagnosis, treatment and the appropriate follow-up of cancer or non-cancer patients; 6) jointly work of organizations - involving national and international institutions to promote joint actions that include continuous education, publication of recommendations and incentives to clinical and experimental research around the theme of opioids; 7) conflict of interest - avoiding the undue influence of entities that have profit in the engagement and bid of opioids to establish the most ethic relationship possible with the prescribers.

Therefore, we can conclude that we must contribute unconditionally for the legitimation of the proper treatment of pain in Brazil and the correct prescription of opioids, monitoring and treating the adverse effects, stratifying the risks and fighting the opiophobia, offering, with sympathy, the relief of pain to the suffering patient.

\author{
Durval Campos Kraychete \\ Universidade Federal da Bahia, Salvador, BA, Brasil \\ (D) https://orcid.org/0000-0001-6561-6584 \\ E-mail:dkt@terra.com.br \\ Joäo Batista Santos Garcia \\ Universidade Federal do Maranhão, São Luís, MA, Brasil. \\ (D) https://orcid.org/0000-0002-3597-6471 \\ E-mail:jbgarcia@uol.com.br
}




\section{REFERENCES}

1. Hastie BA, Gilson AM, Maurer MA, Cleary JF. An examination of global and regional opioid consumption trends 1980-2011. J Pain Palliat Care Pharmacother. 2014;28(3):259-75.

2. Cleary J, Simha N, Panieri A, Scholten W, Radbruch L, Torode J, et al. Formulary availability and regulatory barriers to accessibility of opioids for cancer pain in India: a report from the Global Opioid Policy Initiative (GOPI). Ann Oncol. 2013;24(Suppl 11):xi33-40.

3. Javier FO, Irawan C, Mansor MB, Sriraj W, Tan KH, Thinh DH. Cancer pain management insights and reality in Southeast Asia: expert perspectives from six countries. J Glob Oncol. 2016;2(4):235-43.

4. O'Brien T, Christrup LL, Drewes AM, Fallon MT, Kress HG, McQuay HJ, et al. European Pain Federation position paper on appropriate opioid use in chronic pain management. Eur J Pain. 2017;21(1):3-19.

5. Ahmedzai SH, Bautista MJ, Bouzid K, Gibson R, Gumara Y, Hassan AA, et al. Optimizing cancer pain management in resource-limited settings. CAncer Pain management in Resource-limited settings (CAPER) Working Group.. Support Care Cancer. 2018;21. [Epub ahead of print).
6. Barnett ML, Gray J, Zink A, Jena AB. Coupling Policymaking with Evaluation - The Case of the Opioid Crisis. N Engl J Med. 2017;377(24):2307-9.

7. Gobierno Nacional de la República de Colombia: Ministerio de Justicia y del Derecho - Observatorio de Drogas de Colombia y el Ministerio de Salud y Protección Social, Oficina de las Naciones Unidas contra la Droga y el Delito - UNODC -, Comisión Interamericana para el Control del Abuso de Drogas - CICAD -, Organización de los Estados Americanos - OEA -, Embajada de los Estados Unidos en Colombia - INL -.Estudio nacional de consumo de sustancias psicoactivas en Colombia pp. 63-65, 2013 www.odc.gov.co.

8. International Narcotics Control Board (2015) Availability of internationally controlled drugs: ensuring adequate access for medical and scientific purposes, indispensable, adequately available and not unduly restricted. https://www.incb.org/ documents/Publications/AnnualReports/AR2015/English/Supplement-AR15_availability_ English.pdf. Accessed 6 November 2017.

9. Knaul FM, Farmer PE, Krakauer E, De Lima L, Bhadelia A, Jiang Kwete X, et al. Alleviating the access abyss in palliative care and pain relief an imperative of universal health coverage: the Lancet Commission report. Lancet. 2018;391(10128):1391-454.

10. Garcia JBS, Lopez MPG, Barros GAM, et al. Latin American Pain Federation position paper on appropriate opioid use in pain management. Pain Reports. 2019 [In Press]. 